\title{
Temporary Bearing Method in Construction of Continuous Beam Bridge Erected as Simply-Supported Beam
}

\author{
Mehadi Hassan Rabby ${ }^{1}$, Zhipei Guo², Miaoqiang Huang ${ }^{3}$ \\ ${ }^{1}$ China Civil Engineering Construction Corporation (CCECC), Dhaka, Bangladesh \\ ${ }^{2}$ China Civil Engineering Construction Corporation (CCECC), Beijing, China \\ ${ }^{3}$ China Railway 16th Bureau Group Co. Ltd., Tangshan, China \\ Email: mehedi.ruet11@gmail.com,guozhipei@outlook.com, 511973162@qq.com
}

How to cite this paper: Rabby, M.H., Guo, Z.P. and Huang, M.Q. (2018) Temporary Bearing Method in Construction of Continuous Beam Bridge Erected as Simply-Supported Beam. Open Journal of Civil Engineering, 8, 473-477.

https://doi.org/10.4236/ojce.2018.84033

Received: October 3, 2018

Accepted: November 30, 2018

Published: December 3, 2018

Copyright $\odot 2018$ by authors and Scientific Research Publishing Inc. This work is licensed under the Creative Commons Attribution International License (CC BY 4.0).

http://creativecommons.org/licenses/by/4.0/

\begin{abstract}
The present practice in Bangladesh for erection of girders is placing the girder directly on the bearing pad and joining the adjacent two spans in deck slab level by adopting expansion joints, as the bridges are presently designed as simply-supported beam bridge. The main disadvantage of this type of bridges is that, the seismic resistance is weak, and under the external force beyond the design range, the bridges are more likely to fall in danger because of failure in girders. Also they have expansion joints for each span, which affects the comfort of driving and the overall integrity of the bridge deck is poor [1]. Therefore, design and construction of the bridges have been revised to establish continuity between girders of two adjacent spans and transform the bridge as simply supported continuous beam bridge [2]. Temporary bearing (sandbox) method is proposed in this paper to solve the system transformation of continuous beam bridges. Design of the temporary bearing is very simple and can be manufactured at site. This method has been proved in construction of Arial Kha Bridge and can be applied for other similar bridges in Bangladesh.
\end{abstract}

\section{Keywords}

Temporary Bearing, Simply Supported Span, Simply Supported Continuous Girder, Expansion Joints, Cast-in-Situ Girder Joint Section

\section{Introduction}

Construction of continuous girder bridge is done by launching the girders as simply supported span and the girders of two adjacent spans are made conti- 
nuous by casting the girder end joint section on pier top. To cast the end joint at site, the girders of adjacent two spans need to be placed at their desired position against the permanent bearing pad with the help of temporary support. After gaining the target strength at the "Cast-in-situ" girder joint section, and after completion of stressing and grouting for negative moment tendons, temporary bearing is released and the girder is placed on the permanent bearing pad [3]. The performance of temporary bearings in this method is crucial. Temporary bearings must have sufficient strength, rigidity, stability and ease of disassembly. When the temporary bearing is removed, the beam body can be uniformly and stably placed on the fixed bearing pad. Using this method, construction of the bridge is very smooth and speedy compared to the present practice which has been proved in construction of Arial Kha Bridge.

\section{Design and Calculation}

Temporary bearing generally consists of two hollow cylindrical body connected with a base plate at the bottom. Design of the bearing is very simple and it is based on trial and error method. Following criteria are considered during design of the bearings.

1) Weight of the girder: This weight includes the self-weight of one girder and weight of another girder which will be carried over the girder after placing.

2) No of temporary bearings for one girder: Number of temporary bearing at each end under the girder is taken considering the total load on the bearing and capacity of each bearing.

3) Size of each bearing: Size of different parts of temporary bearing is determined considering the followings.

4) Cylindrical body: Diameter of the cylindrical body is selected considering the lowest free space on pier top against the fixed bearing pad and free space inside the Compressive Strength Testing Machine which will be used for testing capacity of the bearings. Height of the body is selected considering the adjustable height and elevation of the fixed bearing pad at different location.

5) Thickness of the steel plates: Thickness of the steel plates for cylindrical body and base plate is determined by trial and error method considering the total design load on a single temporary bearing.

Cylindrical body is connected with the base plate by continuous welding at both sides of the cylindrical steel body.

6) For Arial Kha bridge, the temporary bearings were designed considering the following data:

a) Weight of each girder $=200$ tons and two temporary bearings were taken at each end under the girder. Therefore, total load on each temporary bearing = $\frac{200}{2 \times 2}+\frac{200}{2 \times 2}=100$ tons Considering weight of girder launcher machine and adding some factor of safety, total load on each bearing was taken as 120 tons = $1200 \mathrm{kN}$. 
b) Thickness of the steel plate was selected by trial method using the compressive strength test for the design load on the bearing. For bottom cylindrical body, thickness of the steel plate was selected as $10 \mathrm{~mm}$ and for top it was taken as $5 \mathrm{~mm}$. Similarly thickness of the base plate was taken as $5 \mathrm{~mm}$.

c) The outer diameter of the cylindrical body was taken as $200 \mathrm{~mm}$ for the bottom cylinder and for top cylinder, it was taken as $240 \mathrm{~mm}$ considering the lowest free space on pier top against the fixed bearing pad and free space inside the compressive strength testing machine. Dimension of the base plate was taken as $300 \times 300 \mathrm{~mm}$ for both top and bottom cylinder.

The detailed dimension of temporary bearing used at Arial Kha Bridge is shown in Figure 1.

\section{Production and Application}

Production of temporary bearings is very simple and it can be done in construction site. First cylindrical body is made, and is welded properly with the base plate. Top cylindrical part is then filled with C30 concrete and is allowed for curing. Bottom part is filled with dry fine sea sand $(\mathrm{FM}=1.2)$ to a specified height according to design elevation of the fixed bearing pad. A valve is set at the bottom part through which sand can be taken out from the cylinder during removal of the bearings.

The temporary bearing is placed against the fixed bearing pad (as shown in Figure 2) and the height is adjusted according to the design elevation. Girder is

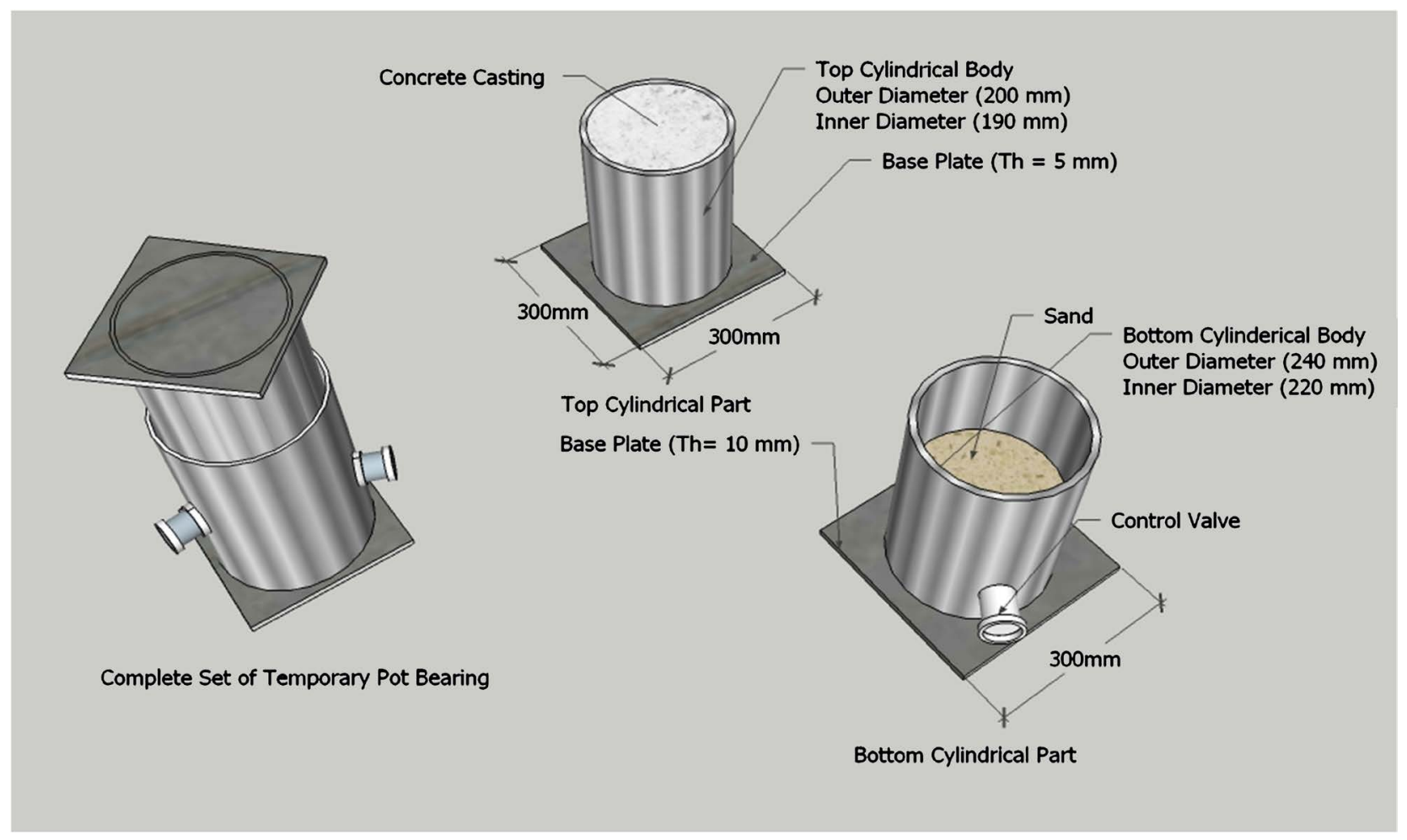

Figure 1. Details of temporary bearing. 
then erected and placed on the temporary bearing and the girders of two adjacent spans are made continuous by casting the joint section above fixed bearing pad. After gaining target strength at "cast in situ concrete", stressing and grouting is done for negative bending moment [4]. The control valve is then opened and sand is flashed away. Thus the temporary bearing is lowered and is taken out for further use.

\section{Case Study}

Temporary bearing method is being successfully applied in construction of Arial Kha Bridge on Dhaka-Khulna (N-8) Highway having total length of 466.48 meters consisting of 10 spans of length 45 meters each. The whole bridge is divided into two parts and connected via expansion joint at mid pier location (Pier \# 05) as the girders are made continuous upto mid length by casting girder joint section on intermediate piers top (Pier \# 1 to $4 \& 6$ to 9). The girders were first placed on temporary bearing to establish continuity between girders by casting the joint section in site. Two temporary bearings were used at each end under the girder having capacity $1200 \mathrm{kN}$ which was confirmed by compressive strength test. Using the temporary bearings, erection of the girders was very smooth and effective. Figure 3 shows the girder launching method and construction progress of Arial Kha Bridge.
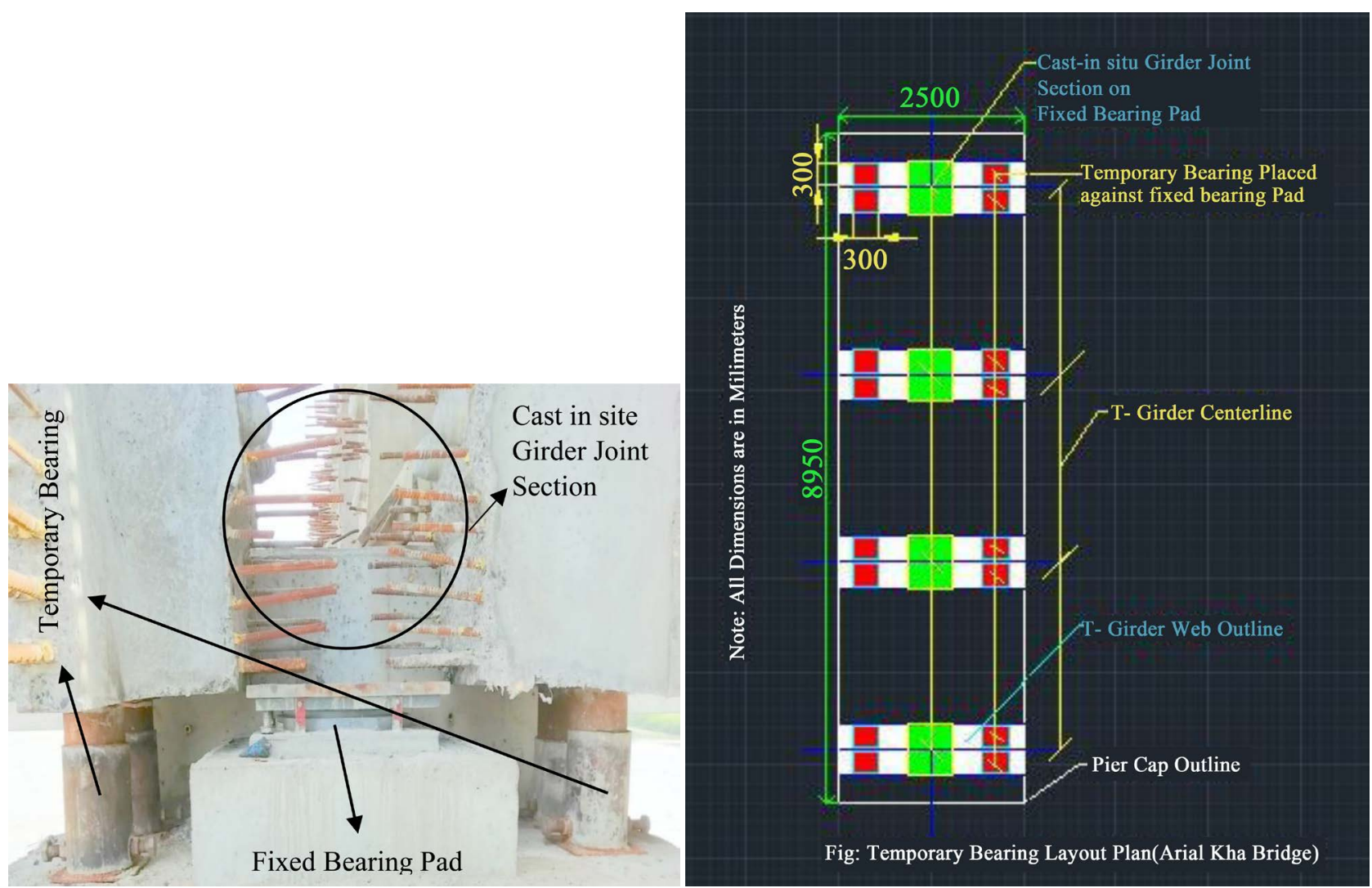

Figure 2. Placement of temporary bearings to support Girders (Arial Kha Bridge, Madaripur, Dhaka). 

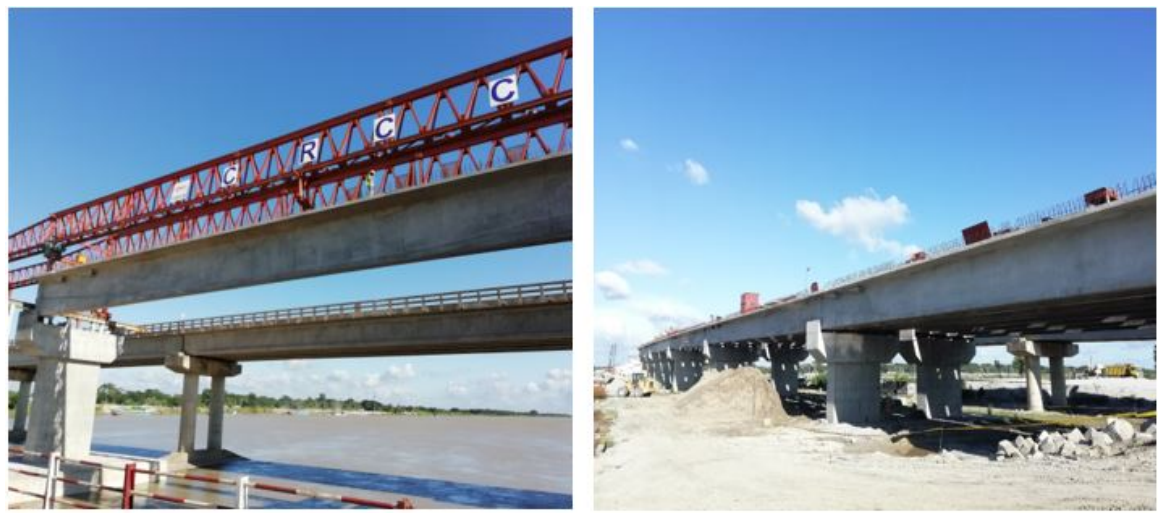

Figure 3. Launching of T-Girder on Temporary Bearing at Arial Kha Bridge, Shibchar, Madaripur, Dhaka, Bangladesh.

\section{Conclusion and Recommendation}

Construction of simply supported continuous girder bridge with temporary bearing is easier and smoother compared to the present practice in Bangladesh as the erection time can be minimized and also number of expansion joint is reduced which is a great achievement in this method. This method also allows a better seismic resistance and improved overall integrity compared to simply supported bridge due to continuity between the spans [5]. Therefore, to have a better serviceability, improved appearance and better ride quality, this method of design and construction of the bridges with temporary bearing may be practiced in Bangladesh as this has been proved in construction of Arial Kha Bridge.

\section{Conflicts of Interest}

The authors declare no conflicts of interest regarding the publication of this paper.

\section{References}

[1] Koch, S. (2008) Prestressed PCBT Girders Made Continuous and Composite with a Cast-in-Place Deck and Diaphragm. Master of Science Thesis, Virginia Polytechnic Institute and State University, Blacksburg, $140 \mathrm{p}$.

[2] Miller, R.A., Castrodale, R.W., Mirmiran, A. and Hastak, M. (2004) Connection of Simple Span Precast Concrete Girders for Continuity. National Cooperative Highway Research Program, Report 519, 203 p.

[3] Bishop, E.D. (1962) Continuity Connection for Precast Prestressed Concrete Bridges. ACI Journal, 59, 585-600

[4] Dimmerling, A., Miller, R.A., Castrodale, R., Mirmiran, A., Hastak, M. and Baseheart, T.M. (2005) Connections between Simply Supported Concrete Beams Made Continuous: Results of National Cooperative Highway Research Program Project 12-53. Transportation Research Record: Journal of the Transportation Research Board, 1928, 126-133.

[5] Hueste, M.B.D., Mander, J.B. and Parkar, A.S. (2012) Continuous Prestressed Concrete Girder Bridges. Volume 1: Literature Review and Preliminary Designs. 